\title{
Biocompatible Magnesium Alloys as Degradable Implant Materials - Machining Induced Surface and Subsurface Properties and Implant Performance
}

\author{
Berend Denkena ${ }^{1}$, Arne Lucas ${ }^{1}$, Fritz Thorey², Hazibullah Waizy², \\ Nina Angrisani ${ }^{3}$ and Andrea Meyer-Lindenberg ${ }^{3}$ \\ ${ }^{1}$ Institute of Production Engineering and Machine Tools, Leibniz Universität Hannover, \\ ${ }^{2}$ Department of Orthopaedic Surgery, Hannover Medical School, \\ ${ }_{3}^{3}$ Small Animal Clinic, University of Veterinary Medicine Hannover,
}

Germany

\section{Introduction}

Annually several million people suffer bone fractures caused by accidents or diseases. Many of those fractures are too complex for an external medical treatment but have to be surgically fixated by internal bone implants. Traditional methods of osteosynthesis or osteotomy use permanent metal implants e.g. bone screws and bone plates made of steel or titanium alloys, but permanent metal implants have to be excised. Especially young patients in growth require the implant removal. Usually, metal implants should be removed latest one or two years after the first surgery. Biodegradable implants, which dissolve in the human organism, therefore represent an appropriate solution. Here magnesium as a degradable implant material provides both biocompatibility and sufficient mechanical properties. Studies have shown that magnesium, which is an essential element of the human organism, is suitable as a degradable biomaterial for use in medical implants. Also in relation to biomechanical requirements the suitability of magnesium as an implant material in has already been proven. Due to mechanical properties superior to the bone, magnesium implants show biomechanical properties comparable to conventional steel implants in standardized biomechanical tests. Also an influence of surface properties on the degradation behavior is already known. Interdisciplinary research between medical and engineering sciences focuses on the development of degradable magnesium implants for osteosynthesis. The removal of those implants after convalescence of the fractured bone is no longer necessary, resulting in a considerable benefit for patients and the public health care system. The aim is to preset individual degradation kinetics for implants made of biocompatible magnesium alloys through adjusting surface and subsurface properties of the magnesium implants for specific indications. Adapted machining processes exhibit possibilities to adjust those properties. The idea of implants specifically adapted to their desired function and functional period within a possible range of surface or subsurface modifications is illustrated schematically in Figure 1for different implant designs (V1 and V2). The healing 
process of a bone is illustrated schematically and opposed to the expected corresponding degradation process of a resorbable implant. Furthermore, possible processes for mechanical machining of the workpieces and modification of the surface and subsurface are illustrated. By means of these processes specific surface and subsurface properties can be adjusted, which, depending on the alloy, can achieve the modification bandwidth illustrated in Figure 1. By means of this modification bandwidth an implantation behavior of the implants during the production process can be achieved specific for each indication.

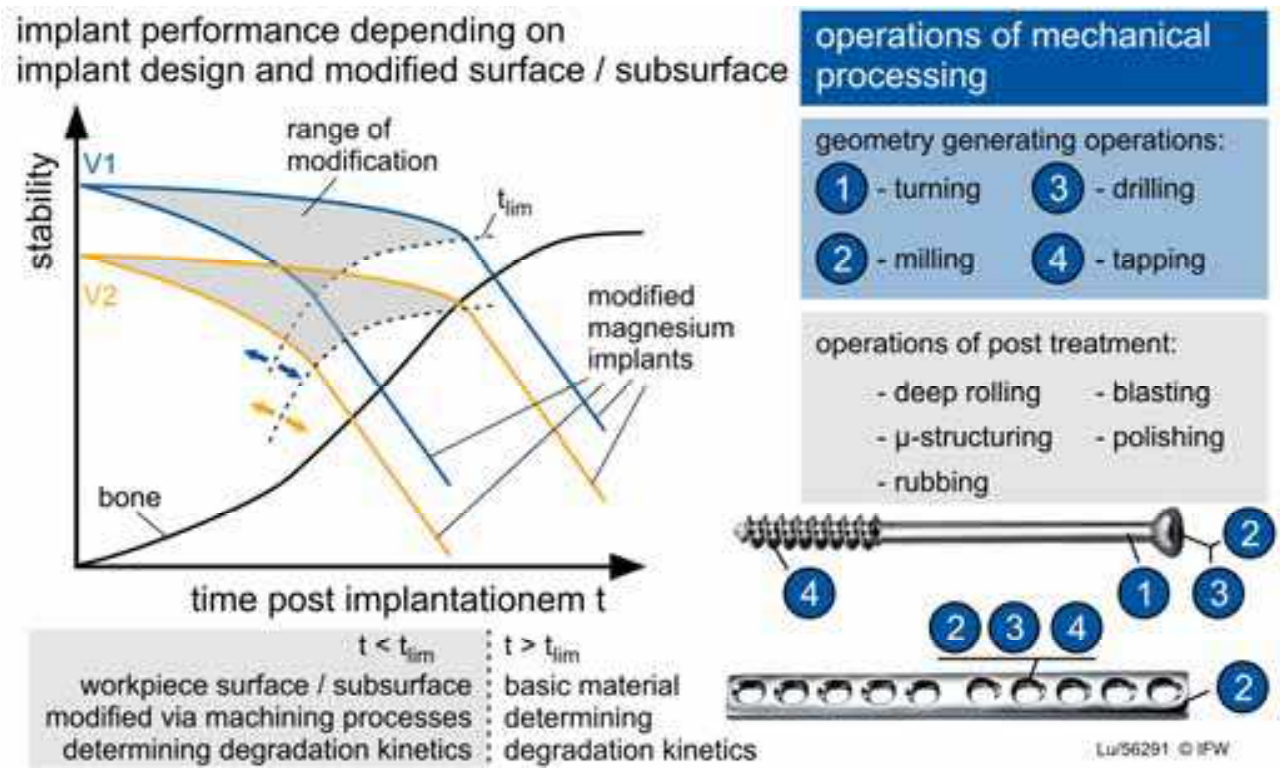

Fig. 1. Scheme of implants adapted to function and applicable machining processes

To adjust specific implant properties, the influence of the mechanical processing on surface and subsurface layers on selected biocompatible magnesium alloys has to be analyzed. Different operations of processing and post-processing magnesium workpieces enable the adjustment of distinct surface and subsurface properties. These properties are then utilized to adjust the corrosion resistance and therefore the degradation kinetics of the implant in the organism. Results of in-vitro an in-vivo experiments validate the strong relation between workpiece properties and corrosion behavior respectively degradation kinetics.

The influence of different processes for the mechanical processing as well as the process input values and process parameters or tool geometries on the workpiece properties and the resulting degradation behavior are investigated on newly developed biocompatible magnesium alloys. Biomechanical characteristics of the samples produced are then analyzed and the influence of the corrosion attack on the biomechanical characteristics of the components is determined in different states of corrosion. In clinical in-vivo trials the degradation kinetics, the profile of biomechanical functions and the osseointegration of various implant demonstrators are investigated. The combination of the results of the invivo and in-vitro studies serves as a basis for the derivation of biomechanically relevant parameters and therefore for a definition of the medical requirements specifically for 
resorbable osteosynthesis implants. In the future, this profile of requirements will determine the implant design, the machining processes and the corresponding process parameters and therefore enables a conception of implants adapted to various indications.

\section{State of science and technology}

In Orthopaedics, implants such as screws, plates, intramedullary nails etc. are utilized for fracture fixation (osteosynthesis). Theses implants, which currently are mainly produced out of steel and titanium materials, are used for the support or fixation of traumatized bones and therefore, in most cases, only have a temporary function until the healing of the bone is completed. The formerly necessary revision surgery, which implies a certain risk for the patient as well as additional costs, can be avoided by utilizing degradable implants. In Orthopaedics and fracture fixation temporary bone implants therefore shall replace more and more permanent osteosynthetic materials, especially in the field of small volume implants (Weiler et al., 2000). These implants temporarily take over the function of the bone for a mechanical stabilization until after gradual degradation they are being replaced by newly built up bone tissue. The temporary implant materials utilized should guarantee a suitable mechanical stability and at the same time be completely degradable and should correspond to the supporting bone (cortical bone) regarding mechanical characteristics to avoid stress shielding (Daniels et al., 1990; Weiler et al., 1998, 2000). Until now, temporary implants are mainly produced out of PLA (polylactic acid, D and L isomers), PGA (polyglycolic acid), TMC (trimethylene carbonate), copolymers with varying substantial ratios, PDS (polydiaxonone) as well as composite materials (calcium phosphate in combination with polymers) (Anker et al., 2005; Ignatius et al., 2001a, 2001b; Sakar et al., 1999; Taylor et al., 1994). The field of application of these materials is however limited due to their relatively low mechanical strength. Therefore they can only be utilized in areas with low tensile, shear and compression forces (Wittenberg et al., 1991). Magnesium-based alloys specifically developed for medical applications offer significantly higher ultimate strengths, a higher Young's modulus and a proven biocompatibility (Niemeyer et al., 2005; Wintermantel \& Ha, 1996).

Chip removing machining processes are generally used for shaping of medical implants because they guarantee a defined influence of the surface and subsurface, in contrast to other techniques such as forming. The flexibility of the design of the sample implants is an additional advantage of cutting machining processes. Regarding the resulting subsurface properties due to the different chip removing machining techniques there are still numerous questions to be answered. Due to the degradation of metallic implants mainly resulting from friction and corrosion, achieving defined subsurface properties in the production of function adapted medical implants is decisive. In the past few years, research on the influence of different surface machining techniques for implants on reactions of the organism has mainly been carried out in the field of dentofacial surgery. Research was mainly done with nonresorbable materials, especially titanium and titanium alloys. The surface topography was the center of attention (Gotz et al., 2004; Nasatzky et al., 2003; Schneider et al., 2003; Shalabi et al., 2006). Further studies showed that of the otherwise identical implants the ones with a thicker oxide layer created by heat treatment of the material lead to an earlier strong implant-bone compound (four weeks after implantation) but also revealed that this difference is being neutralized after a certain time, here 12 weeks after the implantation (Kim et al., 2003). Research on the influence of different shot peening methods during the 
production of roughed surface implants showed, that shot peening of titanium implants with bioceramics in compared to $\mathrm{Al}_{2} \mathrm{O}_{3}$ led to increased bone formation at the implant (Mueller et al., 2003). Though, these studies were carried out on permanent implant materials and therefore, the influence on surface, subsurface and implantation behavior illustrated is not transferrable to the resorbable implant material magnesium.

Besides the machining processes also mechanical surface treatment by means of hardening and softening or micro and macro residual stress can influence the subsurface conditions. Additionally, depending on the process and the parameters, changes of the surface topography can be achieved. These effects can increase the fatigue strength and therefore influence the behavior of the component (Broszeit \& Adelmann, 1996; Scholtes \& Vöhringer, 1996; Scholtes \& Zinn, 1997). Residual compressive stress within the subsurface reduces the intensity of tension at the crack tips and reduces the crack formation and component distortion (Kloos et al., 1988; Nowag et al., 2007; Nüstedt et al., 1996; Brinksmeier et al., 2007). On rotationally symmetric components the supporting proportion could be increased by means of deep rolling. This led to improved operation characteristics as well as a significant improvement of fatigue strength and corrosion resistance. The corrosion speed and therefore the degradation behavior of magnesium-based alloys, besides its composition, especially depend on the surface and subsurface properties after machining. The properties can be adjusted by mechanical processing and it is known that these alterations have an influence on the component properties (Denkena et al., 2006a, 2008; Tomac \& Tonnessen, 1991; Tönshoff et al., 2007; Winkler, 2007). First investigations with biocompatible magnesium alloys already show promising results regarding biomechanical properties and the potential to adjust the corrosion behavior (Denkena et al., 2006b, Denkena \& Lucas, 2007). However, the fundamental relations between the mechanical processing and the resulting surface and subsurface properties of biocompatible magnesium alloys have not yet been investigated. Furthermore, the mechanisms of action of these properties regarding the corrosion behavior and therefore the kinetics of degradation of implants are still unknown. This knowledge is necessary to enable the function adjusted processing of small magnesium implants.

The subsequent biomechanical investigation of resorbable screws, plates etc. regarding biomechanical characteristics for the application in orthopedic surgery, traumatology and maxillofacial surgery is oriented towards the testing of rigid materials. This currently implies the testing of compression forces, pull-out forces, shear strength and bending fatigue strength in corresponding test setups (Carano et al., 2005; DeCoster et al., 1990; Ignatius et al., 2005; Inceoglu et al. 2004; Seebeck et al., 2005; White et al., 2006). The application of synthetic bone out of polyurethane foams according to ASTM-standard F543 is usual (ASTM-Standard F543, 2002). The investigations are carried out on identical testing stands like e. g. the testing device "MTS 858 MiniBionix".

\section{Results}

Firstly, the relations between the particular process input values of the investigated mechanical processes for the production of implants such as cutting parameters, tool geometries or process control variables, regarding the resulting material removal processes and process forces as well as their influence on the surface topography and the subsurface are presented. Based on these findings, the influence of the modified surface and subsurface on the in vitro corrosion behavior is being determined in a time-resolved manner. Parallel the loss of function of implant demonstrators is being correlated to the corrosive weight loss in biomechanical investigations. The in-vivo trials on corrosion behavior and biomechanics 
allow the comparison of the time scales of in-vivo and in-vitro investigations. Considering the different time scales assumptions about the influence of mechanical processing on the degradation kinetics and the expected biomechanical loss of function can be made. The results of the different topic areas "Mechanical Processing", "Clinical in vivo trials" and "Biomechanics" are outlined in the following.

\subsection{Mechanical processing}

The focus of research in the field "Mechanical Processing" is placed on the clarification of the connections between mechanical processing and the in-vitro corrosion behavior. Therefore, the influence of machining processes with different chipping and non-chipping techniques and process kinematics on resulting surface and subsurface properties is analyzed and correlations with the in-vitro corrosion kinetics for different magnesium alloys are developed. All experiments described are carried out on alloys, which were developed for biomedical applications and provided as extruded profiles by the Institute of Material Science (IW) of the Leibniz Universität Hannover (Seitz et al., 2010). Subsequent in-vitro investigations of specifically modified workpieces provide information on the influence of different subsurface conditions on the degradation behavior. In these experiments the corrosion behavior is analyzed quantifiable and time-resolved.

As a result, the parameters, which generate high passive forces (rolling pressure, cutting edge rounding), prove to be most significant. This passive force acts normally to the workpiece surface and is therefore significantly involved in the work hardening of the subsurface. The modification bandwidth of the corrosion behavior is significantly influenced by the surface properties (micro topography of the workpiece surface) and the residual compressive stress profile in the subsurface. The possibility for the modification of the corrosion kinetics by means of the subsurface condition also strongly depends on the alloy utilized. With the described machining processes and procedures also implant demonstrators were produced for biomechanical testing and clinical in vivo trials.

\subsubsection{Characterization of the workpiece subsurface after machining}

The comprehensive characterization of the workpiece subsurface after machining provides information on the influence of cutting conditions and process parameters on the machining result. The interactions between different machining techniques, cutting materials, tool geometries and process parameters are investigated regarding plastic deformation of the surface, burr formation, surface quality and modification of the subsurface. Therefore the surface topography is analyzed by tactile and optical methods. Furthermore, a specially equipped SEM is used, which also serves for the EDX analysis of material components and corrosion products. In cooperation with the IW micro computer tomographic $(\mu-\mathrm{CT})$ analysis of corroded workpieces are carried out. In the characterization of the machined samples the depth-influence of the machining processes were especially focused on. Therefore, the subsurface is characterized by means of depth resolved micro hardness profiles, structural analysis and residual stress depth profiles. To be able to detect the residual stress condition, residual stress depth profiles for each of the differently machined samples are generated with an X-ray diffractometer using the $\sin ^{2}-\Psi$-method.

\subsubsection{Studies on the machining influence under turning kinematics}

On rotationally symmetric workpieces machining processes with rotational kinematics are applied. Deep rolling is used for the post processing of previously turned samples. 
Experiments to compare the capability of influencing properties of different materials were carried out on the alloys MgCa0.8 and MgCa3.0. Therefore, samples of both materials are machined by means of turning and deep rolling at identical process parameters. Rolling forces of $50 \mathrm{~N}$ and $200 \mathrm{~N}$ are adjusted via the hydraulic pressure of the hydrostatic deep rolling tool Ecoroll HG6, in which a hard material ball rolls over the workpiece surface.
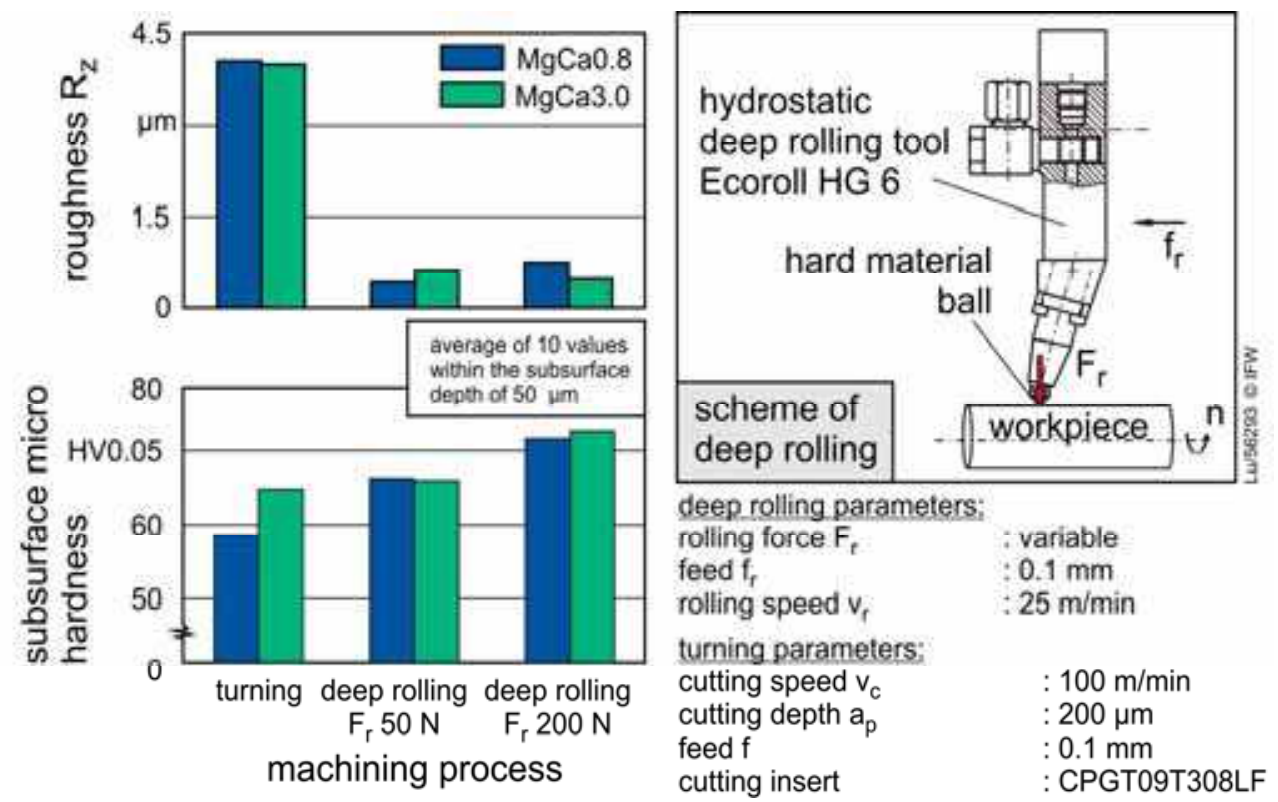

Fig. 2. Influence on surface and subsurface after turning and deep rolling

Some of the surface and subsurface properties resulting from processing are shown in Figure 2 and Figure 3 show. The surface quality is significantly improved by the deep rolling process whereas no differences concerning the alloy can be detected. In addition to this, an increase in hardness of the subsurface is achieved by increasing the rolling pressure. This becomes more obvious in the MgCa0.8 alloy, which is of lower basic hardness. Deep rolling as a post processing method provides the possibility to induce residual compressive stress in the subsurface.

Figure 3 shows the induced residual stress for $\mathrm{MgCa} 0.8$ and $\mathrm{MgCa} 3.0$. After turning, only a minor influence on the residual stress very closely under the surface can be detected in both alloys. After deep rolling, though, a strong shift of the residual stress profile in the compressive direction can be detected. By means of a rolling force of $50 \mathrm{~N}$ a higher residual stress maximum of approx. $150 \mathrm{MPa}$ at a low depth is achieved whereas it is only $120 \mathrm{MPa}$ for a rolling force of $200 \mathrm{~N}$. A rolling force of $200 \mathrm{~N}$, though, achieves an influenced depth of approx. $800 \mu \mathrm{m}$.

The results for different rolling forces correspond with the fundamental physical correlations of the Hertzian contact stress. Both alloys show similar subsurface properties and therefore similar possibilities of modification from the mechanical machining processes applied. The resulting corrosion characteristics will be described in a chapter below. 


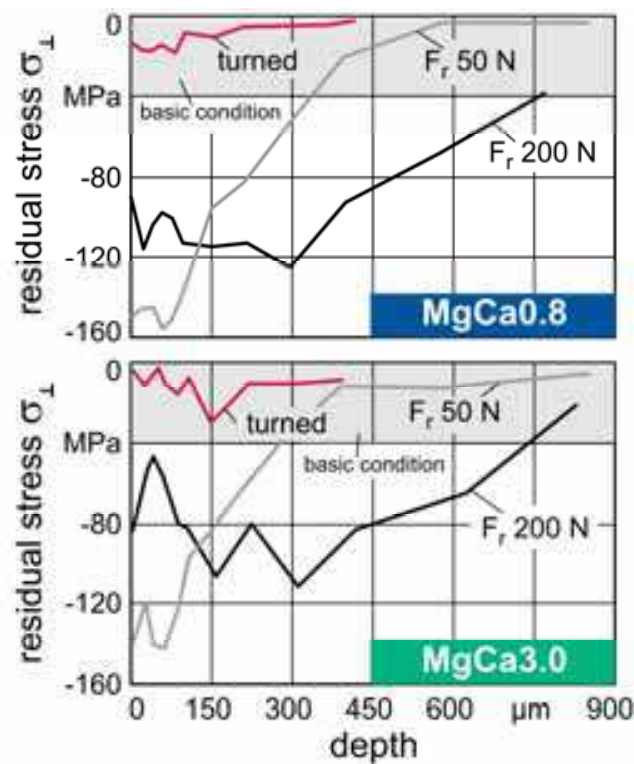

\begin{tabular}{|lr|}
\hline x-ray device: & $\begin{array}{r}\text { Seifert } \\
\text { XRD } 3000 \mathrm{P} \\
\mathrm{Cu} / \mathrm{Ni}\end{array}$ \\
radiation: & $35 \mathrm{kV}, 35 \mathrm{~mA}$ \\
& $\mathrm{PSD}$ \\
detector: & $2 \Theta_{0}=118.6^{\circ}$ \\
reference angle: & $2 \mathrm{~m}^{\circ}$ \\
max. penetration depth: $60 \mu \mathrm{m}$
\end{tabular}

\begin{tabular}{|c|c|}
\hline $\begin{array}{l}\text { rolling force } F_{t} \\
\text { feed } f_{r} \\
\text { rolling speed } v_{t} \\
\text { deep rolling tool }\end{array}$ & $\begin{array}{l}\text { : variable } \\
: 0.1 \mathrm{~mm} \\
: 25 \mathrm{~m} / \mathrm{min} \\
\text { : Ecoroll HG } 6\end{array}$ \\
\hline
\end{tabular}

\section{turning parameters:}

cutting speed $v_{c}$

cutting depth $\mathrm{a}_{\mathrm{p}}$

feed $f$

cutting insert

depth
$100 \mathrm{~m} / \mathrm{min}$

$200 \mu \mathrm{m}$

$0.1 \mathrm{~mm}$

CPGT09T308LF

Lusarso oifw

Fig. 3. Manipulation of subsurface after turning and deep rolling

\subsubsection{Studies on the machining influence under milling kinematics}

To be able to analyze in the influence of milling processes on surface and subsurface properties, magnesium cylinders of the alloy $\mathrm{MgCa} 0.8$ are face-milled. Therefore, process parameters are systematically varied and different tools are used. Following, the results from the investigations with milling tools, that were utilized with sharp edged $\left(\mathrm{r}_{\beta}<10 \mu \mathrm{m}\right)$ and modified cutting edges are shown. To modify the tools, the edges were prepared with cutting edge radii of $r_{\beta}=100 \mu \mathrm{m}$ and $r_{\beta}=200 \mu \mathrm{m}$ by means of brushing. Figure 4 shows the SEM-pictures of the tool variants, an icon of the face-milling process and the resulting surface qualities after milling.

At low cutting speeds, the surfaces created by honed tools are significantly rougher than on the samples machined with sharp cutting edges. The rounding leads to an undefined cutting process and therefore to increased formation of scratches and flakes. This effect disappears at higher cutting speeds and therefore increased thermal energy in the deformation zone in front of the cutting edge. Rising temperatures and increasing ductility of the material obviously lead to a smearing of the scratches and flakes and therefore a smoothing of the surface when using honed tools. The surface qualities resulting are similar to those of sharp tools.

By using honed cutting edges in face milling also a significant influence on the subsurface is achieved. Figure 5 shows that subsurface properties regarding the residual stress profile are generated, that are similar to those after deep rolling. While sharp tools hardly cause changes in the subsurface, honed cutting edges induce residual compressive stresses up to approx. $400 \mu \mathrm{m}$ of depth. The penetration depth can be increased by advanced rounding. A residual stress maximum of up to $-120 \mathrm{MPa}$ can be achieved for both roundings. The maximum for the rounding of $\mathrm{r}_{\beta}=200 \mu \mathrm{m}$ can be located at a depth of approx. $100 \mu \mathrm{m}$ and 
therefore a little deeper than for the rounding of $\mathrm{r}_{\beta}=100 \mu \mathrm{m}$ for which is located at a depth of approx. $70 \mu \mathrm{m}$. The penetration depth of influence can be increased from approx. $200 \mu \mathrm{m}$ to approx. $400 \mu \mathrm{m}$ be means of increased cutting edge rounding.
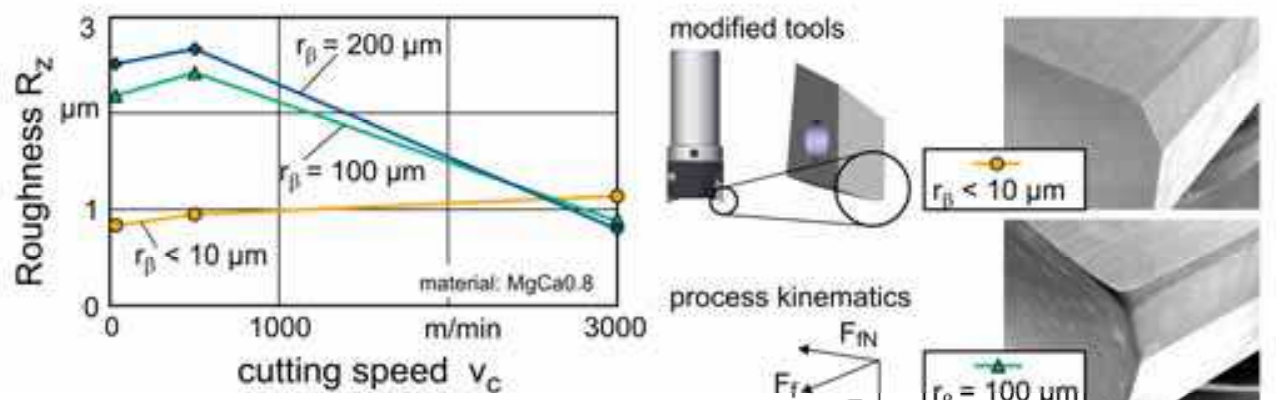

milling parameters:

cutting speed $\mathrm{v}_{c}$

foed por tooth $f_{z}$

cutting edge radius $r_{p}$

depth of cut a.

cutting insert

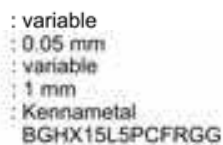

process kinematics
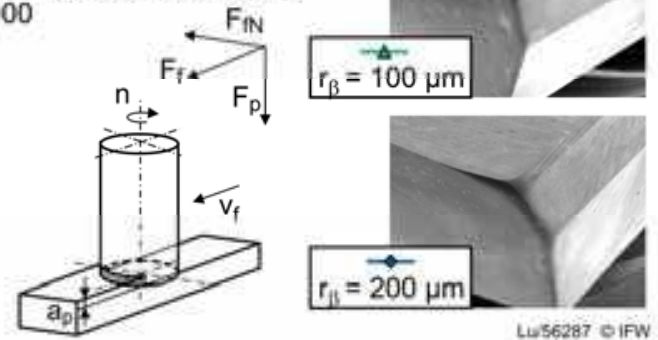

Fig. 4. Modified tools and surface qualities after milling
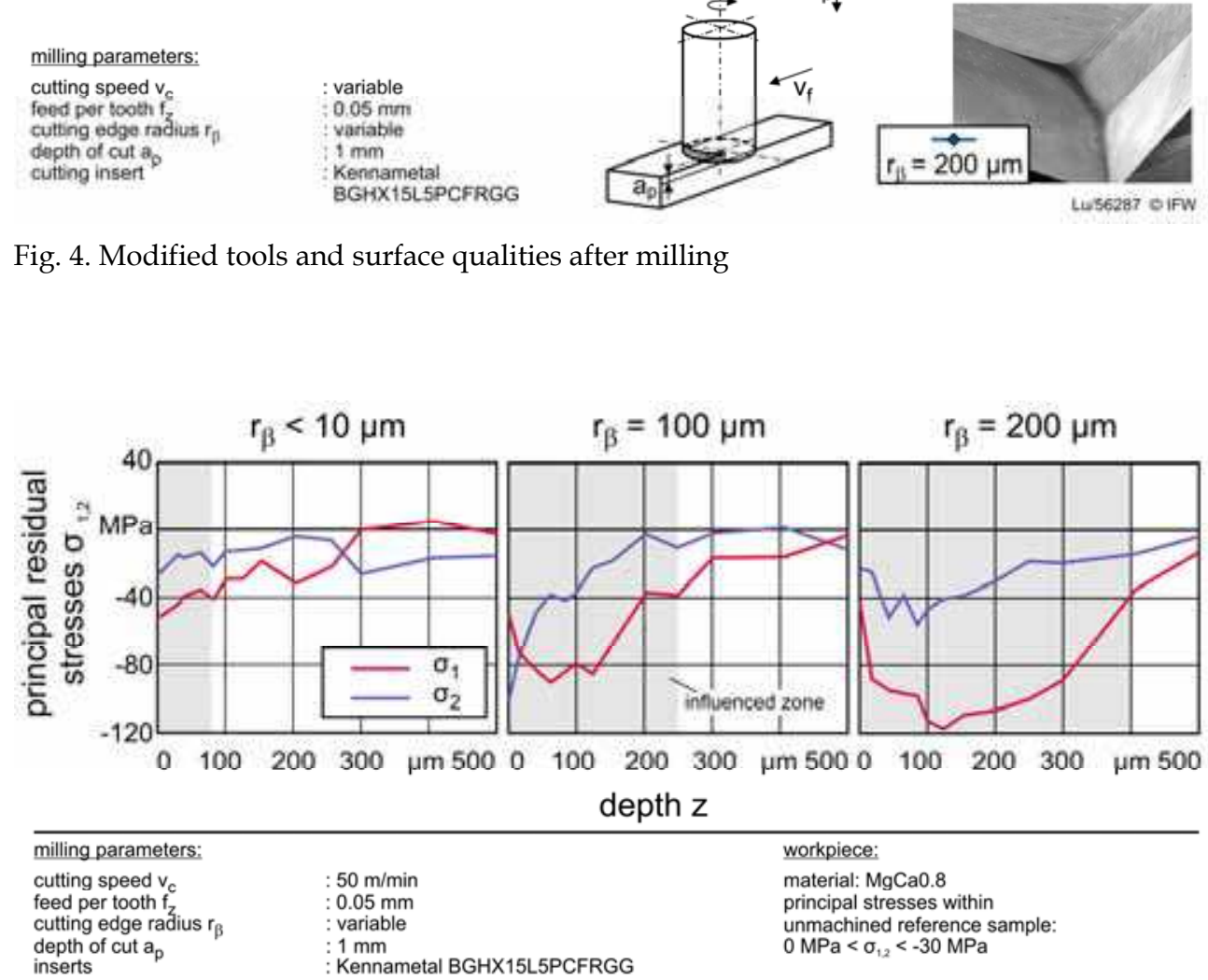

LuS6287 OIFW

\begin{tabular}{lll} 
& \multicolumn{1}{c}{ depth $\mathbf{Z}$} & \\
\hline milling parameters: & $: 50 \mathrm{~m} / \mathrm{min}$ & workpiece: \\
cutting speed $\mathrm{v}_{\mathrm{c}}$ & $: 0.05 \mathrm{~mm}$ & material: MgCa0.8 \\
feed per tooth $\mathrm{f}_{z_{i}}$ & $:$ variable & principal stresses within \\
cutting edge radius $\mathrm{r}_{\beta}$ & $: 1 \mathrm{~mm}$ & unmachined reference sample: \\
depth of cut $\mathrm{a}_{\mathrm{p}}$ & $:$ Kennametal BGHX15L5PCFRGG & $0 \mathrm{MPa}<\sigma_{12}<-30 \mathrm{MPa}$ \\
inserts & &
\end{tabular}

Fig. 5. Influenced subsurface after milling with modified tools 


\subsubsection{Correlation of results of studies on turning and milling}

To correlate the results of the studies on turning and milling, test series are carried out, in which similar process parameters are adjusted. Therefore similar chip thicknesses result for both machining methods. That is especially, because the residual stress is measured in the center of the milling path, where the chip thickness equals the feed per tooth. In both processes extruded materials $(\varnothing=20 \mathrm{~mm})$ are used, which are turned to a diameter of $\varnothing=18 \mathrm{~mm}$ respectively milled into a half cylinder. Furthermore, turning and milling tools are prepared with similar cutting edge roundings (sharp $r_{\beta}<10 \mu \mathrm{m}, r_{\beta}=100 \mu \mathrm{m}$, $\mathrm{r}_{\beta}=200 \mu \mathrm{m}$ ). Therefore, analogical relations exist between chip thickness and cutting edge radii. The results of the residual stress measurements illustrated in Figure 6 show similar tendencies in the depth profiles of the workpieces after turning and milling. There is only a minor modification of the subsurface for sharp tools. With increased rounding of the cutting edge squeezing effects and therefore plastic deformation of the material close to the surface increases, which induces residual compressive stress into the subsurface. This effect becomes even more significant in milling at increased cutting edge radii.

Comparing the depth of impact of both processes, significant differences are detectable. In turning a depth influence of approx. $100 \mu \mathrm{m}$ can be achieved, which cannot be increased by doubling the radius of the cutting edge. In milling with modified tools of $r_{\beta}=100 \mu \mathrm{m}$ a depth of influence of up to approx. $200 \mu \mathrm{m}$ can be achieved and for $\mathrm{r}_{\beta}=200 \mu \mathrm{m}$ a depth of up to approx. $400 \mu \mathrm{m}$.

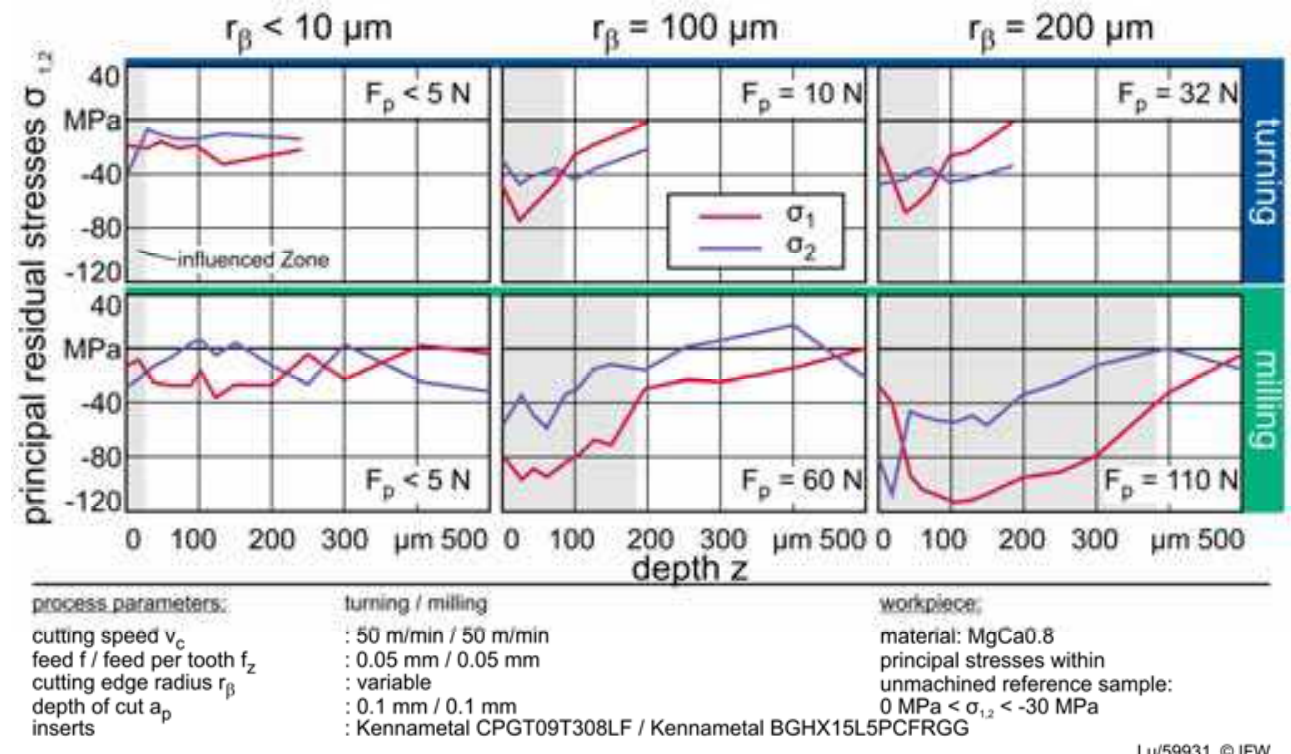

Fig. 6. Comparison of the subsurface modification after turning and milling

The forces in passive direction can be considered as the main cause of this effect. These forces $\left(\mathrm{F}_{\mathrm{p}}\right)$ directed normally toward the surface of the workpiece are on a higher level for milling than for turning. The continuous chip generation in turning with rounded tools obviously leads to a jam of material in front of the cutting edge. The jammed material does 
not flow neither over the cutting edge, nor below and therefore acts like a built-up edge. The negative effective rake angle resulting form the rounding of the cutting edge therefore does not come into effect and only a minor increase of the passive force is detected. The milling process shows that at the applied low cutting speed no ordinary built-up edge is generated. In discontinuous cutting the edge cannot form from jammed material because the height of the point of stagnation varies with the varying undeformed chip thickness and, in addition to this, the tool periodically gets out of contact with the work material.

The discontinuous milling process also lies on a lower temperature level due to the cutting edge cooling in the interruption of cut. Furthermore, the machined surface and therefore the volume for a similar feed distance is larger in the turning process (proportional to the circumference $U=56.5 \mathrm{~mm}$ at $\varnothing=18 \mathrm{~mm}$ ) than in the milling process (width of milling path $b=20 \mathrm{~mm}$ ). The thermal influences inducing tensile residual stress are therefore lower in the milling process and the mechanical influences inducing compressive residual stress dominate. This is also confirmed by the residual stress of the surface, which hardly exceed $-40 \mathrm{MPa}$ in turning while in milling up to $-80 \mathrm{MPa}$ are achieved.

\subsubsection{In vitro corrosion studies of the samples mechanically machined}

After analyzing the surface modifications and the depth effects of the subsurface modifications caused by machining processes, in vitro corrosion studies are performed, to examine the relation between these modifications and the impact on the corrosion behavior, especially on the corrosion profile over the time. It was observed how the corrosion characteristics of implants with modified subsurfaces change over time with regard to environmental influences. This provides information on the period of time in which the modified subsurface has an influence on the corrosion and degradation behavior of the implant ( $t_{\lim }$ in Figure 2). To be able to determine the influence of the modification of the surface and subsurface on the corrosion behavior, the corrosion progress of different subsurface modifications is monitored time-resolved and analyzed in the corrosion experiments.

Different surface and subsurface properties are adjusted on similar sample geometries in order to analyze the time behavior of the degradation induced by the machining. In the in vitro corrosion studies in physiological $\mathrm{NaCl}$ solution $(0.9 \mathrm{wt} \% \mathrm{NaCl}$ in deionized water) carried out. The mass of the corroding magnesium can be determined via continuously monitoring volume of the generated hydrogen released during the oxidation of magnesium. The samples are produced by means of the chip removing and non-chip removing processes described earlier.

The studies on the machining influence on different magnesium materials revealed a major difference in the ability to influence different alloys, considering the corrosion. While the surface and subsurface properties resulting from machining are similar for both materials MgCa0.8 and MgCa3.0 (see above) the corrosion behavior of the two differs significantly. Only a minor influence of the mechanical processing on the resulting corrosion kinetics was revealed for MgCa0.8. Figure 7 and Figure 8 show that a very similar corrosion progress was revealed for turning and deep rolling of $\mathrm{MgCa} 0.8$ despite very different surface and subsurface properties. The $\mu$-CT analyzes are performed in cooperation with the IW. 

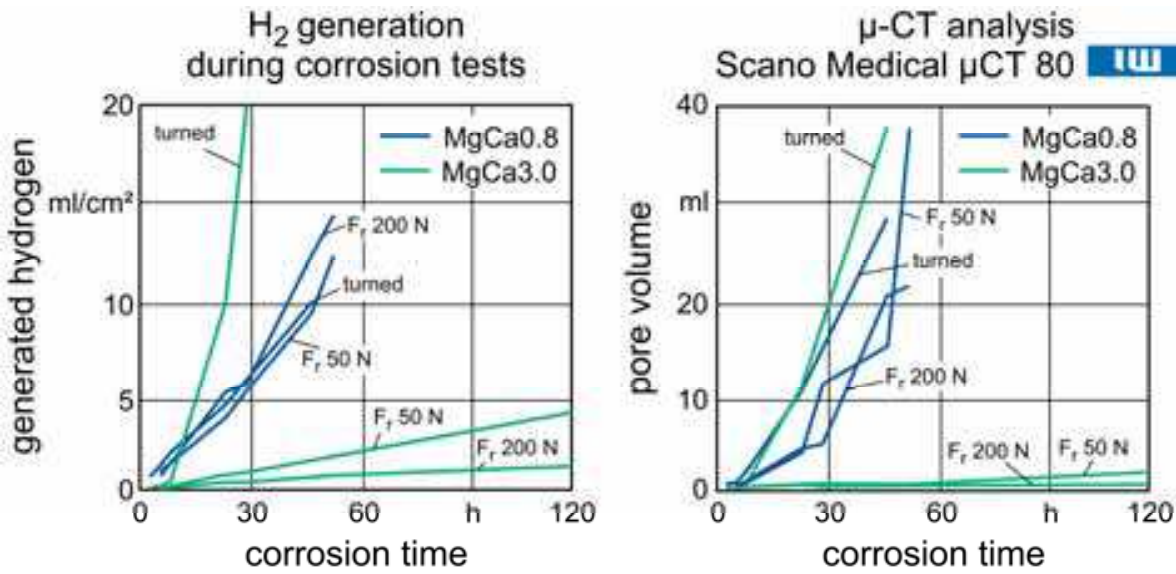

deep rolling parameters: rolling force $F_{r}$ feed $\mathrm{f}_{\mathrm{r}}$

: variable

rolling speed $v_{r}$ deep rolling tool

$0.1 \mathrm{~mm}$

$: 25 \mathrm{~m} / \mathrm{min}$

: Ecoroll HG 6 turning parameters:

cutting speed $\mathrm{v}_{\mathrm{c}}$

cutting depth $a_{p}$

feed $f$

cutting insert
: $100 \mathrm{~m} / \mathrm{min}$

$: 200 \mu \mathrm{m}$

: $0.1 \mathrm{~mm}$

: CPGT09T308LF

Fig. 7. Corrosion kinetics of turned and deep rolled samples of different material

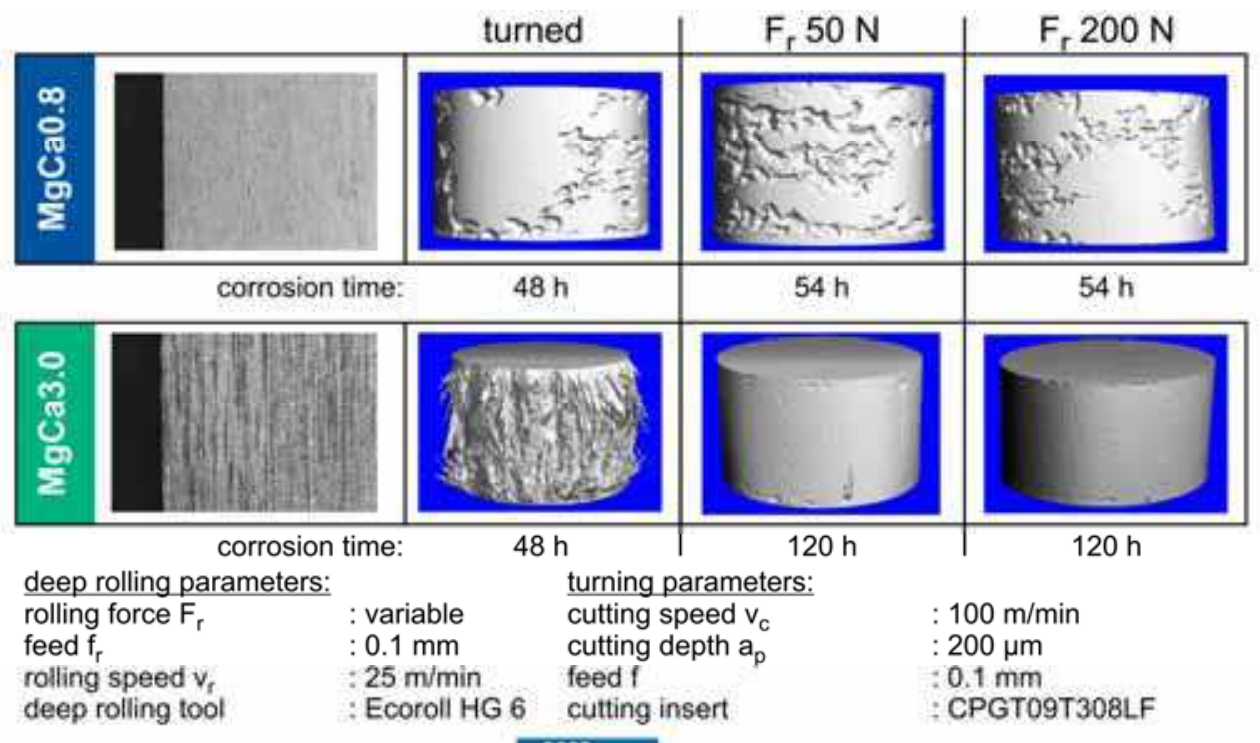

$\mu$-CT analysis: Scano Medical $\mu \mathrm{CT} 80$

Fig. 8. Corrosion morphology of turned and deep rolled samples of different material

The records of the release of hydrogen during the corrosion (Figure 7) as well as the evaluation in the $\mu$-CT of the samples that were analyzed after a certain time (Figure 8, top) 
show that no significant differences concerning the corrosion behavior of $\mathrm{MgCa} 0.8$ are detectable for the machining methods and process parameters applied. The corrosion rates are at a similar level. The alloy MgCa3.0, though, showed a significantly different corrosion behavior. This alloy shows a strong sensitivity of the corrosion behavior towards the modification of the subsurface. The corrosion progresses monitored by means of the hydrogen generation over time (Figure 7) as well as the samples studied after certain corrosion times in the $\mu$-CT (Figure 8 bottom) show a strong influence of the mechanical processing. A significant reduction of the corrosion rate can be achieved by means of deep rolling. A difference in the corrosion rates of MgCa3.0 in turned and deep rolled samples by a factor of up to 100 is proved by the corrosion studies. The turned MgCa3.0 samples are attacked very strongly and their surface is undermined and then even bursting by the corrosion attack. The corrosion in deep rolled samples progresses delayed and very homogenously. In contrast to the homogenous structure of $\mathrm{MgCa} 0.8$ in which the calcium is dissolved interstitially, in $\mathrm{MgCa} 0.3$ the phase of the less noble $\mathrm{Mg}_{2} \mathrm{Ca}$ is attacked stronger. The deep rolling process obviously has an effect of closing superficial mirco-pores and additionally the residual compressive stresses induced avoid a superficial formation and propagation of cracks. This prevents the corrosion front from progression toward the center of the workpiece and the subversion of the surface. This in turn results in an overall homogenous corrosion attack. Thus, besides the basic corrosion rate of an applied alloy not only the surface and subsurface properties are decisive for influencing the corrosion rate. But also the characteristics of the alloy regarding its micro structural composition and crystallization are of great importance in the achievable modification bandwidth. Therefore it can be distinguished between materials with a corrosion behavior sensitive to machining and those that can be modified only very limitedly.

\subsection{Clinical in vivo trials}

The connection between the surface and subsurface properties and the in vivo degradation behavior as well as the resulting biomechanical loss of function of implant demonstrators is investigated in the field "Clinical in vivo trials". Therefore, the degradation kinetics of magnesium implants of different surfaces, subsurfaces and geometries were studied in experiments on rabbits.

\subsubsection{Studies on cylindrical implant demonstrators}

To study the influence of the mechanical processing on the surface and subsurface of cylindrical implant demonstrators and their corresponding corrosion behavior, a magnesium calcium alloy with a calcium content of $0.8 \%$ is chosen. This shows good results in both, in vitro and in vivo pilot studies. Smooth and sandblasted implants as well as threaded cylinders out of $\mathrm{MgCa} 0.8$ are studied. Besides the testing of the in vivo corrosion characteristics also the biocompatibility in the implant-bone bonding and the osseointegration are tested. The cylinders are implanted into the cortico-spongy transition area of the medial condyle of femur and remained for evaluation periods of 3 and 6 months. Besides clinical and radiological monitoring $\mu$-CT scans are made to evaluate the existence of bone formation, gas accumulations and the state of degradation of the implants at the end of the trial period and after explantation of the distale fermur. Then, the non-decalcified bone-implant-compound is embedded in artificial resin and analyzed histological, after the 
preperation of microtome sections. Further, the histological cross sections of the cylinders are studied by means of an SEM, including EDX.

The investigations verify results from pilot studies: the sandblasted cylinders show the highest level of degradation and a $n$ early loss of shape, the smooth cylinders degrade very slowly and homogeneously and the threaded cylinders show local corrosion attacks in the crest areas of the thread (Figure 9).

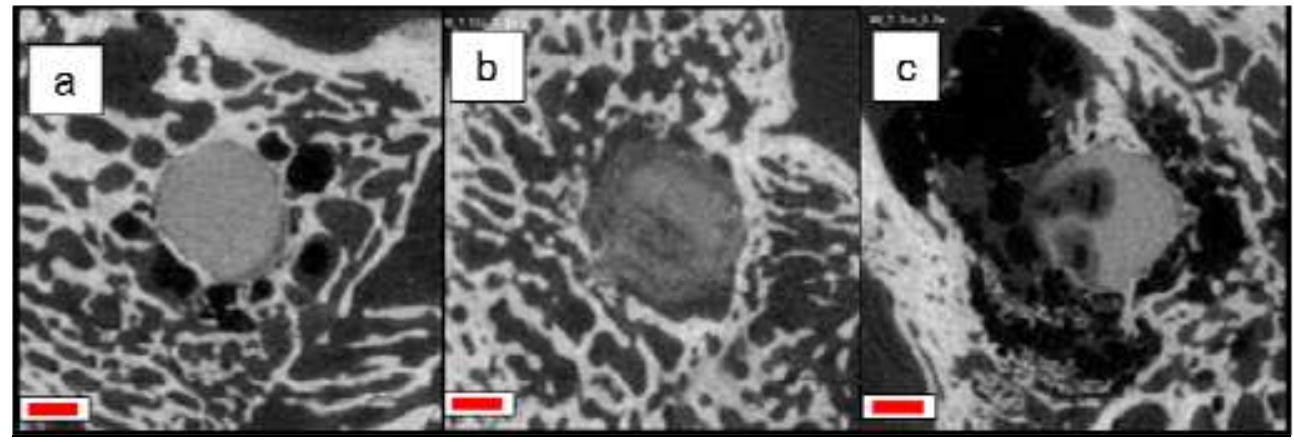

Fig. 9. $\mu$-CT scans of a smooth cylinder (a), sandblasted cylinder (b) and threaded cylinder (c) in the condyle of femur six months after implantation in the rabbit

The generation of gas as well as the biocompatibility correlates with the state of degradation. The faster degrading sandblasted cylinders show the strongest generation of gas with clearly visible bubbles under the skin in close vicinity to the implant in $50 \%$ of the cases. Lymphocytes, plasma cells and foreign body cells, as signs of the immune response of the organism, appear most frequently in the tissue around the sandblasted implants. Smooth cylinders do not show any gas accumulations and the cellular reactions are minimal. The gas accumulation on the threaded cylinders is moderate. It was mostly only diffuse and small accumulations that appeared in the tissue. All of the implants led to the formation of small patches of cartilaginous tissue around the implants, which can be seen as an early stage of the remodeling of the bone. The further development of these patches has to be analyzed in studies over longer implantation periods. A slower and more consistent degradation as seen with the smooth implants is more favorable because the reaction of the surrounding tissue is the lowest.

\subsubsection{Studies of screw geometries}

The osseointegration of screw geometries after different implantation periods $(2,4,6$ and 8 weeks) is tested. Due to the screw dimensions, the cortico-spongy transition area of the distal femur proved to be inappropriate in pre-tests. Therefore the screws are implanted in the lateral tibia of the rabbit at the level of the insertion site of the fibula. Screws out of the magnesium alloy $\mathrm{MgCa} 0.8$ and surgical steel 316L are utilized. The production of the screw occurs following the in vitro tests (comparable thread pitch and flank width) to be able to compare in vitro and in vivo results. During the testing period, clinical, radiological and in vivo $\mu$-CT examinations are carried out, especially to evaluate the degree of bony and emphysematous formations. Even during the trials, an evaluation on the degradation of the $\mathrm{Mg}$ screws could be carried out via of the $\mu-\mathrm{CT}$ data. 


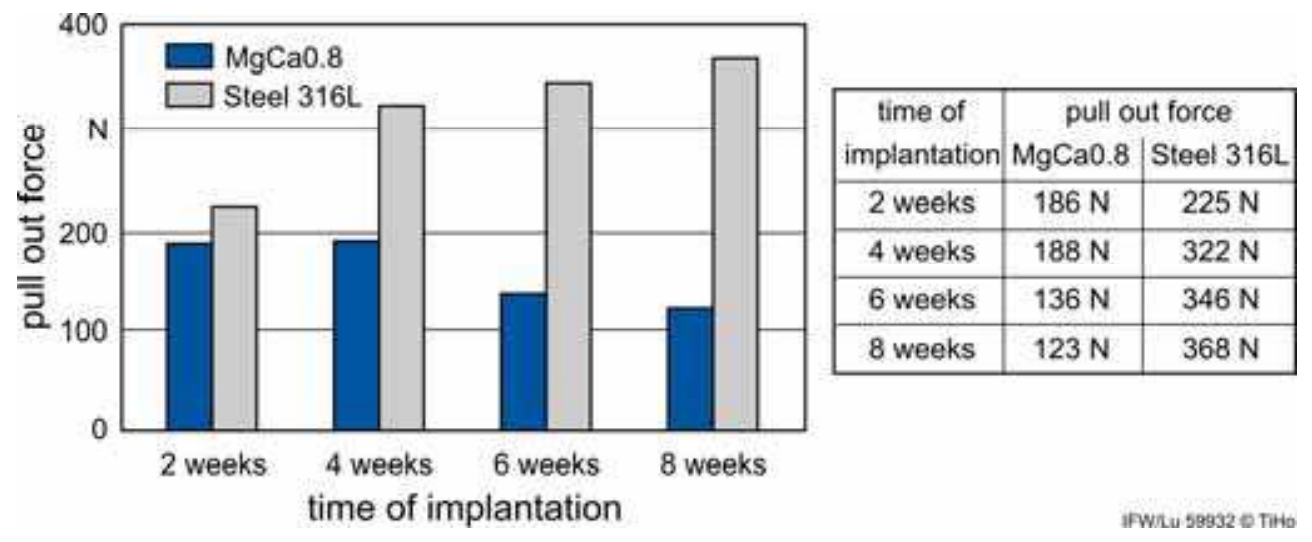

Fig. 10. Tensile forces of resorbable MgCa0.8 and permanent 316L steel screws after different implementation periods

At the end of the evaluation period the strength of the implant-bone compound is tested by biomechanical examinations: to evaluate the degree of osseointegration and biodegradation pull-out tests are carried out (Figure 10). A special test set-up was established that allows to pull out the screw demonstrators with geometries from the in vivo studies as well as from the in vitro studies for comparison. The pull-out tests show no significant difference between the maximum pull-out forces of $\mathrm{MgCa} 0.8$ and surgical steel after an implantation period of two weeks. The maximum pull-out force of $\mathrm{MgCa} 0.8$ hardly decreased within the first four weeks after the implantation. Only in the long term, a continuous decreasing of the pull-out forces is detected. In contrast to that, the pull-out force of surgical steel continuously increases during the period of implantation. Therefore, significantly higher pull-out forces are measured for the surgical steel after four, six and eight weeks. Eventually, the screws were analyzed in toto and, after embedding in artificial resin, in thick-sections by means of SEM and EDX.

The muscles situated above the screw head (M. tibialis cranialis) are examined histological to evaluate the biocompatibility of the screws. The prepared paraffin sections were stained with H\&E staining and analyzed (Figure 11). The histological analysis of the peri-implant tissue shows similar results for both implant materials, which proves the formation of a fibrotic layer between the screw head and the covering muscles. Macrophages, foreign body cells and heterophile granulocytes as well as small patches of necrotic tissue are identified. The analysis focuses on the evaluation of the degree of fibrosis (thickness of fibrotic layer), necrosis and the cellular infiltration (amount of macrophages, foreign body cells, heterophile granulocytes) and is carried out by means of semi-quantitative scoring (nonexistent, insignificant, low-grade, medium-grade, high-grade, very high-grade). In the group of steel implants the thickness of the connective tissue, the degree of cellular infiltration and the necrosis decreases continuously. A decrease of the parameters analyzes also appears in the $\mathrm{MgCa} 0.8$ group, however only the first four to six weeks after surgery. At the end of the implantation period the parameters analyzed increase.

Immunhistochemical staining is applied to show CD3 and B-CD79 $\alpha$, by which small amounts of T- and B-lymphocytes are detectable in both groups (MgCa0.8 and steel 316L). In comparison to steel, fewer T-lymphocytes and more B-lymphocytes are traced in the $\mathrm{MgCa} 0.8$ group. 


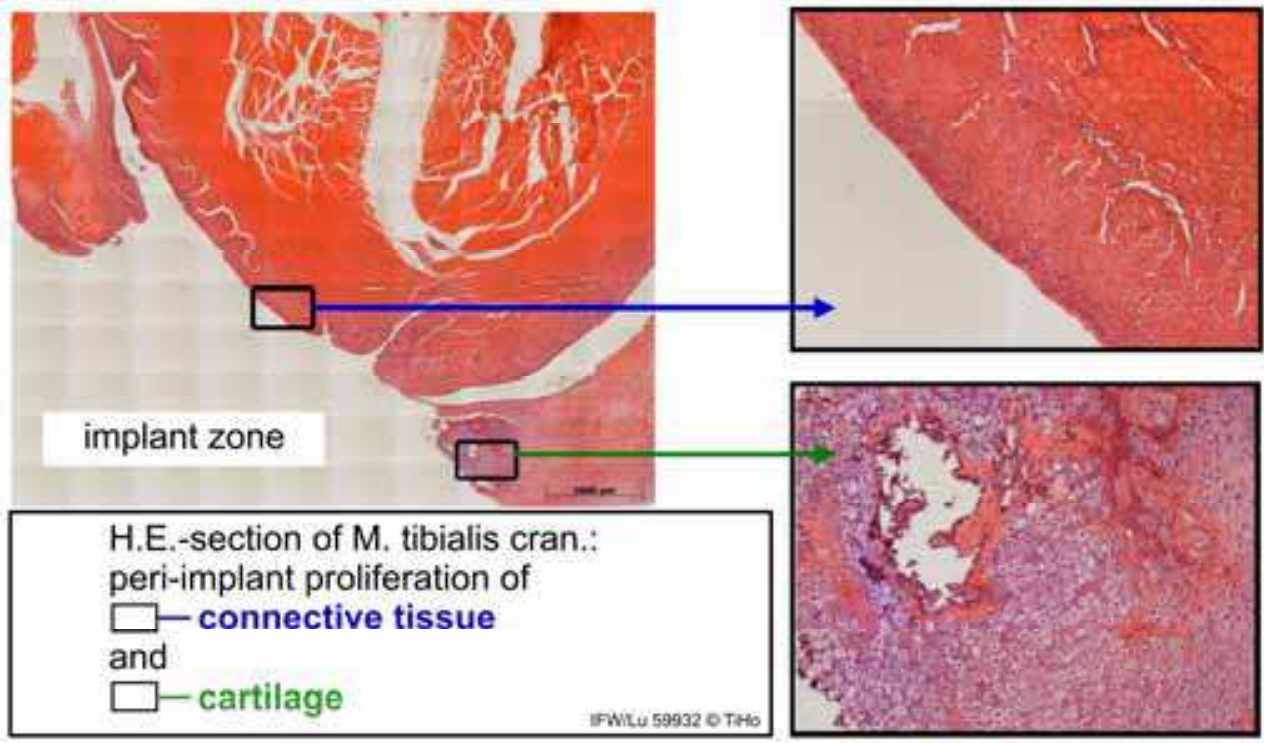

Fig. 11. Histological scans of a muscle section after the implantation of an $\mathrm{MgCa} 0.8$ screw

\subsection{Biomechanics}

In the field of "Biomechanics", the influence of modified surface and subsurface conditions on the in vitro corrosion behavior under different loads is analyzed and the biomechanical loss of function due to degradation of the material is modeled. The performance of the implant demonstrators are tested in vitro under dynamic stresses. Different stresses of the samples are reproduced in biomechanical test setups. The analysis of components in graded states of corrosion provides information on the loss of function as a result of geometry changes and mass loss due to corrosion.

A newly developed and established corrosion test stand outlines the loss of function depending on the corrosion progress. The corrosion stand can be divided into three subunits. The flow velocity is adjustable by a peristaltic pump, the first unit. The thermostat as a further unit indirectly warms up the corrosion solution, which is led through a heat bath. The temperature of the solution is checked by means of a thermometer before it flows into the corrosion chamber. The corrosion chamber is the third unit, which is adjustable for each demonstrator-geometry. The chamber design ensures a laminar flow within the corrosion chamber. The significant factors of corrosion such as flow velocity, temperature of the solution and its composition are adjustable in the corrosion stand. Hence, the influences of the modified surface and subsurface conditions on the in vitro corrosion behavior under static and dynamic stresses and the biomechanical loss of function due to degradation of the material can be determined.

\subsubsection{Static stress with and without corrosion}

The aim of the investigation is to determine the maximum pull-out force without influence of the corrosive medium. MgCa0.8 screws with an outer diameter of $4 \mathrm{~mm}$, a core diameter 
of $3 \mathrm{~mm}$ and a thread pitch of $1 \mathrm{~mm}$ are applied in this test. They are inserted into artificial bone out of polyurethane (SYNBONE AG, Neugutstrasse 4, CH- 7208 Malans). Density of cortical plate: $0.72 \mathrm{~g} / \mathrm{cm}^{3}+/ 5 \%$; Density of cancellous bone: $37 \mathrm{~kg} / \mathrm{m}^{3}$ (DIN EN ISO 845). By means of a biomechanical test device (Bionix-MTS 14000, Technology Drive Eden Prairie, MN USA) the screws are exposed to an axial pull-out force that was linearly increased until the compound between screw and artificial bone failed.

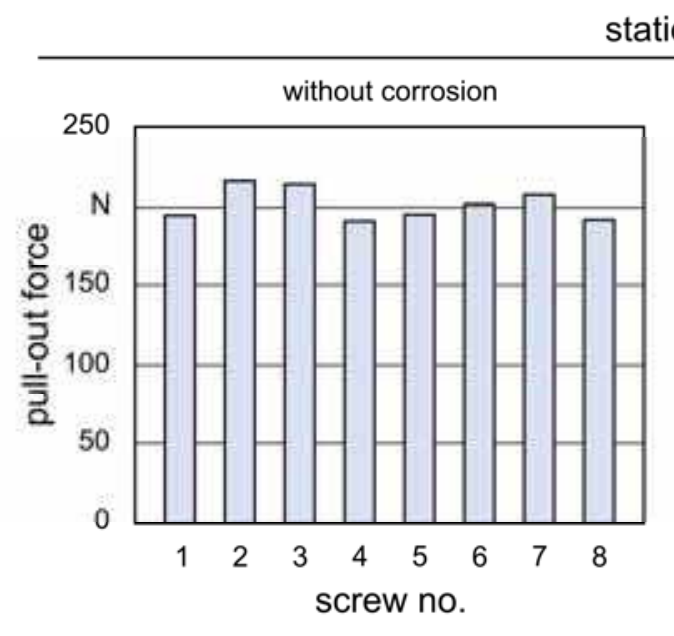

static loading

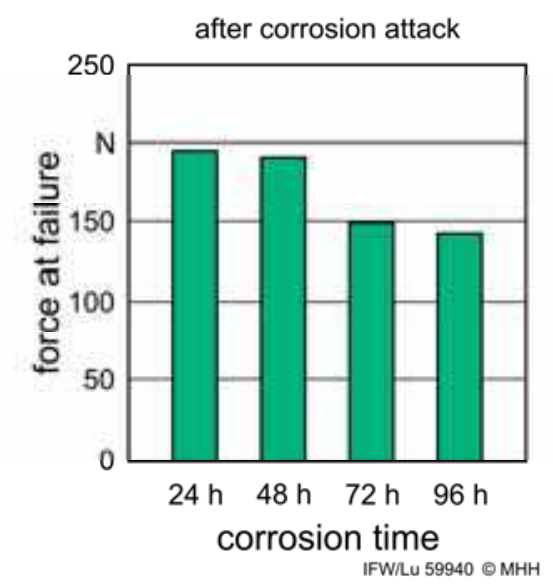

Fig. 12. Pull out forces of screw demonstrators (left) and mean value of the force at failure after $24 \mathrm{~h}, 48 \mathrm{~h}, 72 \mathrm{~h}, 96 \mathrm{~h}$ of corrosion for groups of 8 screws (right)

In each test series eight screws are used. The results for the demonstrators without corrosion show a reproducible bone-screw fixation at a low standard deviation. This data serves as a reference value for the determination of the failure load of the bone-screw compound at different states of corrosion. The left diagram in Figure 12 shows an average pull-out force of $201.5 \mathrm{~N}$ at a standard deviation of $9.3 \mathrm{~N}$ that appeared in the pull-out tests.

To detect the remaining maximum pull-out force after corrosion $(24 \mathrm{~h}, 48 \mathrm{~h}, 72 \mathrm{~h}$ and $96 \mathrm{~h})$ $\mathrm{MgCa} 0.8$ screws of an outer diameter of $4 \mathrm{~mm}$, a core diameter of $3 \mathrm{~mm}$ and a thread pitch of $1 \mathrm{~mm}$ are applied. In the test stand they are inserted into the artificial bone out of polyurethane. The flow rate of the used HANK's solution is set to $2 \mathrm{ml} / \mathrm{h}$ at an adjusted temperature of $37^{\circ} \mathrm{C}$. After fixed intervals, the screws were stressed until failure by means of the MTS test device. For each corrosion period eight screws were tested: $8 / 24 \mathrm{~h} ; 8 / 28 \mathrm{~h}$; $8 / 72 \mathrm{~h} ; 8 / 96 \mathrm{~h}$. The maximum tensile force decreases under the influence of corrosion over time (see Figure 12, right) and the preliminary assumptions were therefore verified.

\subsection{Correlation of biomechanical results in vitro / in vivo}

For the design of implants and the prediction of the implant behavior in vitro results have to be correlated with those from the clinical in vivo experiments. Figure 13 shows similar tendencies in the development of biomechanical characteristics over time in both environments. A continuous function loss of the screw demonstrators is proved after corrosion in vitro and degradation in vivo, respectively. Furthermore, a strong scaling of the 
behavior over time becomes obvious. While the decrease of the tensile force of approx. $30 \%$ occurs within $100 \mathrm{~h}$ in vitro, a similar function loss in vivo only occurs after about $1000 \mathrm{~h}$. The time profiles of the investigated biomechanical characteristics therefore are accelerated ten times approximately under in vitro conditions.

\section{Loss of the biomechanical function of screw demonstrators due to degradation}

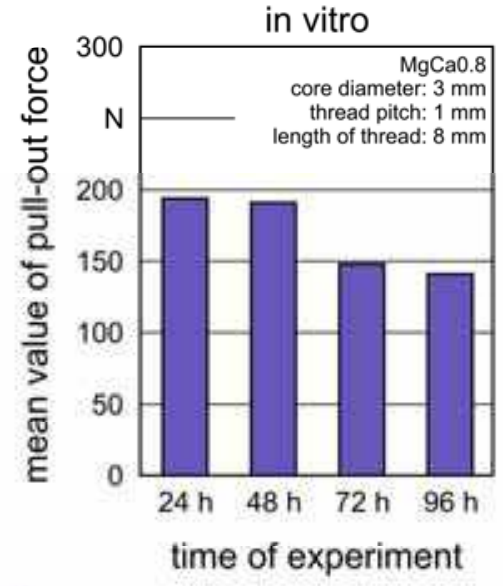

$\diamond$ corrosion liquid: tempered HANK's solution standardised artificial bone substitute in vivo

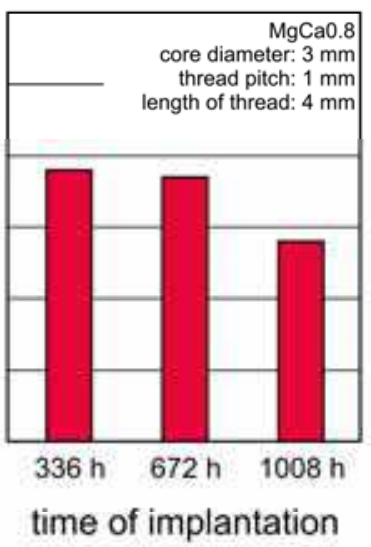

in vitro sample after $96 \mathrm{~h}$ of corrosion attack

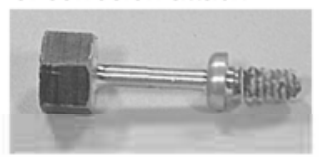

in vivo sample

$336 \mathrm{~h}$ post $\mathrm{OP}$

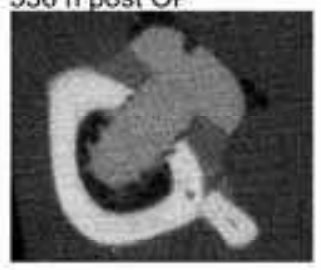

Fig. 13. Comparison of the biomechanical loss of function in vivo and in vitro

\section{Conclusion and outlook}

Revision surgeries on implants are a significant cost driver in public health care. Avoiding the material removal surgeries, resorbable implants out of magnesium therefore offer a great potential for cost reduction. Additionally, the patient is not unnecessarily put to risk.

The works presented focus on the idea of "intelligent osteosynthesis" in which implants with a specific degradation profile are subjected to a stability loss, which is adjusted to the increasing stability of the healing bone. The presented results show that specific surface and subsurface modifications can be achieved by means of adapted machining processes and for suitable alloys the resulting corrosion behavior can be adjusted in vitro and the degradation profile in vivo, respectively. Biomechanical tests prove a continuous stability loss due to degradation in vitro and in vivo.

In the future, the application of resorbable implants enables new areas of indication by the development of implant designs adapted to the material and the expected degradation as well as by new methods for the production including an adapted mechanical processing of these magnesium implants. Producing these implants in industrial production processes that guarantee specific implant properties without exceeding the production costs of currently used implants will be challenging. To enable the clinical application and achieve the marketability for load bearing resorbable magnesium implants, future tasks will focus the development and adaptation of the production technology and the adjustment of 
specific implant properties corresponding with the geometrical implant design. At sufficient stability, fatigue strength, resulting in a stable osteosynthesis until completion of the bone healing, the field of application of load bearing resorbable implants can be made accessible.

\section{Acknowledgments}

The investigations described in this paper were funded by the German Research Foundation (DFG) within the subproject R4 of the collaborative research center SFB 599 "Sustainable Bioresorbable and Permanent Implants of Metallic and Ceramic Materials".

\section{Reference}

Anker, C. J.; Holdridge, S. P., et al. (2005). Ultraporous beta-tricalcium phosphate is well incorporated in small cavitary defects. Clin. Orthop. Relat. Res., 434:251-257

ASTM-Standard F543. (2002). Annual Book of ASTM Standards, Philadelphia, Pennsylvania/USA: American Society for Testing and Materials

Brinksmeier, E., Garbrecht, M., Meyer, D., \& Dong, J. (2007) Surface hardening by strain induced martensitic transformation. Production Engineering, (2)2:109-116

Broszeit, E., \& Adelmann, J. (1996). Schwingfestigkeitssteigerung durch Festwalzen - Grundlagen und Anwendung. Broszeit, E.; Steindorf, H. (Eds.). Mechanische Oberflächenbehandlung. DGM Informationsgesellschaft Verlag, Oberursel, pp. 63-82

Carano, A., Lonardo, P., Velo, S., \& Incorvati, C. (2005). Mechanical properties of three different commercially available miniscrews for skeletal anchorage. Prog Orthod., 6(1):82-97

Daniels, A. U., Chang, M. K., et al. (1990). Mechanical properties of biodegradable polymers and composites proposed for internal fixation of bone. I Appl. Biomater, 1:57-78

DeCoster, T. A., \& Heetderks, D. B., et al. (1990). Optimizing bone screw pullout force. burnal of Orthopaedic Trauma, 4(2):169-174

Denkena, B., Alpers, P., Weinert, K., \& Hammer, N. (2006). Influence of Cutting and Non-

Cutting Processes on the Corrosion Behavior and the Mechanical Properties of Magnesium Alloys. Production Engineering, XIII(1):1-4

Denkena, B., Podolsky, C., van der Meer, M., \& Lucas, A. (2006). Machining of Permanent and Bioresorbable Implants Made of Ceramics and Magnesium. Production Engineering, XIII(1):13-18

Denkena, B., Boehnke, D., \& de León, L. (2008). Machining induced residual stress in structural aluminum parts. Production Engineering, 2(3):247-253

Denkena, B., \& Lucas, A. (2007). Biocompatible magnesium alloys as absorbable implant materials - Adjusted surface and subsurface properties by machining processes. Annals of the CIRP, 56(1):113-118

Gotz, H. E., Muller, M., et al. (2004). Effects of surface finish on the osseointegration of lasertreated titanium alloy implants. Biomaterials, 25(18):4057-64

Ignatius, A. A., Augat, P., Hollstein, E., Schorlemmer, S., Peraus, M., Pokinskyj, P., \& Claes, L. (2005). Biocompatibility and functionality of the degradable polymer alkylene bis(dilactoyl)-methacrylate for screw augmentation in vivo. JBiomed Mater Res. $B$ Appl Biomater, 75(1):128-136 
Ignatius, A. A., Betz, O., et al. (2001). In vivo investigations on composites made of Resorbable ceramics and poly(lactide) used as bone graft substitutes. CI Biomed. Mater. Res. 58:701-709

Ignatius, A. A., Ohnmacht, M., et al. (2001) A composite polymer/tricalcium phosphat membrane for guided bone regeneration in maxillofacial surgery. $\mathrm{el}$ Biomed. Mater. Res. 58:564-569

Inceoglu, S., Ferrara, L., \& McLain, R. F. (2004). Pedicle screw fixation strength: pullout versus insertional torque. Spine el, 4(5):513-518,

Kim, Y. H., Koak, J. Y., et al. (2003). A histomorphometric analysis of the effects of various surface treatment methods on osseointegration. Int J Oral Maxillofac Implants, 18(3):349-356

Kloos, K. H., Adelmann, J., et al. (1988). Oberflächen- und Randschichteinflüsse auf die Schwingfestigkeitseigenschaften. VDI-Berichte, 661:215-245

Mueller, W. D.; Gross, U.; et al. (2003). Evaluation of the interface between bone and titanium surfaces being blasted by aluminium oxide or bioceramic particles. Clin Oral Implants Res., 14(3):349-356

Nasatzky, E., Gultchin, J., et al. (2003). The role of surface roughness in promoting osseointegration. Refuat Hapeh Vehashinayim, 20(3):8-19, 98

Niemeyer, M., Windhagen, H., et al. (2001). Magnesiumlegierungen als degradabler Werkstoff für die medizinische Anwendung. Biomedizinische Technik, Ergänzungsband, 46(1):238-239

Nowag, L., Sölter, J., \& Brinksmeier, E. (2007). Influence of turning parameters on distortion of bearing rings. Production Engineering, 1(2):135-139

Nüstedt, H. (1996). Beitrag zum Ermüdungsverhalten superleichter Magnesium-LithiumBasislegierungen, Dr.-Ing. Dissertation, Universität Hannover

Sakar, M., Bakker, F. C., et al. (1999). Biobon - ein Calciumphosphat-Zement zur Auffüllungknöcherner Defekte. Ergebnisse der klinischen Pilotstudie mit 49 Patienten. Unfallchirurg, 275:238-239

Schneider, G. B., Perinpanayagam, H., et al. (2003). Implant surface roughness affects osteoblast gene expression. JDent Res., 82(5):372-376

Scholtes, B., \& Vöhringer, O. (1996). Grundlagen der mechanischen Oberflächenbehandlung;

Broszeit, E., \& Steindorf, H. (Eds.). Mechanische Oberflächenbehandlung, DGM Informationsgesellschaft Verlag, Oberursel, pp. 3-20

Scholtes, B., \& Zinn, W. (1997). Mechanische Oberflächenbehandlung von Leichtbauwerkstoffen, Frieling, E., Martin, H., \& Tikal, F. (Eds.). Neue Ansätze für innovative Produktionsprozesse, Kassel University Press, Kassel, pp. 376-383

Seebeck, J., Goldhahn, J., Morlock, M. M., \& Schneider, E. (2005). Mechanical behavior of screws in normal and osteoporotic bone. Osteoporos Int., 16(2):107-111

Seitz, J. M., Wulf E., Freytag, P., Bormann, D., \& Bach, F. W. (2010). The Manufacture of Resorbable Suture Material from Magnesium. Advanced Engineering Materials, 12(11):1099-105

Shalabi, M. M., Gortemaker, A., et al. (2006). Implant surface roughness and bone healing: a systematic review. JDent Res., 2006 85(6):496-500

Taylor, M. S., Daniels, A. U., et al. (1994). Six bioabsorbable polymers: in vitro acute toxicity of accumulated degradation products. I Appl. Biomater., 5:151-157 
Tomac, N., \& Tonnessen, K. (1991). Formation of Flank Build-Up in Cutting Magnesium Alloys, Annals of the CIRP, 40(1):79-82

Tönshoff, H. K., Haferkamp, H., et al. (2001). Einfluss des Festwalzens auf die Oberflächen- und Randzoneneigenschaften der Magnesiumlegierung AZ31 und AZ91, Sonderband Magnesiumtechnologie. Materialwissenschaft und Werkstofftechnik

Weiler, A. M., Hoffmann, R. F. G., et al. (2000). Biodegradable implants in sports medicine. The biological base. Arthroscopy, 16:305-321

Weiler, A. M., Windhagen, H. J., et al. (1998). Biodegradable interference screw fixation exhibits pull-out force and stiffness similar to titanium screws. Am. I Sports Med, 26:119-126White, K. K., Oka, R., Mahar, A. T., Lowry, A., \& Garfin, S. R. (2006). Pullout strength of thoracic pedicle screw instrumentation: comparison of the transpedicular and extrapedicular techniques. Spine, 31(12):E355-E358

Winkler, J. (2000). Herstellung rotationssymmetrischer Funktionsflächen aus Magnesiumwerkstoffen durch Drehen und Festwalzen, Dr.-Ing. Dissertation, Universität Hannover

Wintermantel, E., \& Ha, S. W. (1996). Biokompatible Werkstoffe und Bauweisen, Springer, Berlin, Heidelberg, New York

Wittenberg, J. M., Wittenberg, R. H., et al. (1991). Biomechanical properties of resorbable poly-Llactide plates and screws: a comparison with traditional systems. $\mathcal{O}$ Oral Maxillofac. Surg., 49:512-516 


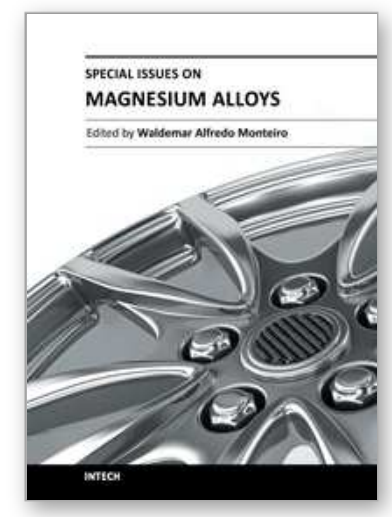

\author{
Special Issues on Magnesium Alloys \\ Edited by Dr. Waldemar Monteiro
}

ISBN 978-953-307-391-0

Hard cover, 128 pages

Publisher InTech

Published online 12, September, 2011

Published in print edition September, 2011

Magnesium is the lightest of all the metals and the sixth most abundant on Earth. Magnesium is ductile and the most machinable of all the metals. Magnesium alloy developments have traditionally been driven by requirements for lightweight materials to operate under increasingly demanding conditions (magnesium alloy castings, wrought products, powder metallurgy components, office equipment, nuclear applications, flares, sacrificial anodes for the protection of other metals, flash photography and tools). The biggest potential market for magnesium alloys is in the automotive industry. In recent years new magnesium alloys have demonstrated a superior corrosion resistance for aerospace and specialty applications. Considering the information above, special issues on magnesium alloys are exposed in this book: casting technology; surface modification of some special Mg alloys; protective carbon coatings on magnesium alloys; fatigue cracking behaviors of cast magnesium alloys and also, magnesium alloys biocompatibility as degradable implant materials.

\title{
How to reference
}

In order to correctly reference this scholarly work, feel free to copy and paste the following:

Berend Denkena, Arne Lucas, Fritz Thorey, Hazibullah Waizy, Nina Angrisani and Andrea Meyer-Lindenberg (2011). Biocompatible Magnesium Alloys as Degradable Implant Materials - Machining Induced Surface and Subsurface Properties and Implant Performance, Special Issues on Magnesium Alloys, Dr. Waldemar Monteiro (Ed.), ISBN: 978-953-307-391-0, InTech, Available from: http://www.intechopen.com/books/special-issues-onmagnesium-alloys/biocompatible-magnesium-alloys-as-degradable-implant-materials-machining-inducedsurface-and-subsurf

\section{INTECH}

open science | open minds

\section{InTech Europe}

University Campus STeP Ri

Slavka Krautzeka 83/A

51000 Rijeka, Croatia

Phone: +385 (51) 770447

Fax: +385 (51) 686166

www.intechopen.com

\section{InTech China}

Unit 405, Office Block, Hotel Equatorial Shanghai

No.65, Yan An Road (West), Shanghai, 200040, China 中国上海市延安西路65号上海国际贵都大饭店办公楼405单元

Phone: +86-21-62489820

Fax: +86-21-62489821 
(C) 2011 The Author(s). Licensee IntechOpen. This chapter is distributed under the terms of the Creative Commons Attribution-NonCommercialShareAlike-3.0 License, which permits use, distribution and reproduction for non-commercial purposes, provided the original is properly cited and derivative works building on this content are distributed under the same license. 